\title{
NOTA DEL EDITOR
}

\author{
ANDRÉS A. ESCALANTE
}

La Facultad de Negocios de la Universidad Peruana de Ciencias Aplicadas (UPC), presenta mediante esta nota editorial el primer número del tercer volumen de su Review of Global Management. Quienes formamos parte, tanto de su Comité Ejecutivo, como de su Comité Editorial Internacional, nos sentimos complacidos de la publicación del presente número porque esta revista no sólo resume una ardua labor colectiva de corte operativo, sino también y sobre todo un esfuerzo institucional por diseminar erudición por la vía escrita. Ello, apelando a la reflexión intelectual, al pensamiento crítico y a la investigación científica, en temas de interés académico, como de actualidad, relevantes en la administración de empresas, negocios internacionales, innovación, emprendimiento y economía, entre otros.

Esta revista tiene el firme propósito de proveer al lector de conocimiento. Puntualmente, su objetivo es el de exponer ideas y sentires; desarrollar herramientas y métodos; generar información y análisis; e implementar buenas prácticas internacionales. Todo ello para mejorar la toma de decisiones empresariales; para entender el alcance social y económico de las mismas; para fomentar el emprendimiento empresarial y el intra-emprendimiento en las organizaciones; para estimular la innovación, generadora de eficiencias de gestión y desarrolladora de más y mayores mercados en un entorno lógicamente incierto, en el que la globalización forja, entre agentes económicos remotos, una competencia permanente por los consumidores, por el lado de la demanda y, por el lado de la oferta, por el capital natural, el capital virtual, el capital físico y sobre todo el capital humano.

En cuanto a su desarrollo temático y tenor, en esta revista se apuesta porque el enfoque del problema sea fundamentalmente analítico. Se pretende, entonces, que prime el uso del razonamiento lógico para vertebrar la máxima utilidad de la investigación, la que, como notase Schultz, casi ochenta años atrás, no está en función del uso de las herramientas o de los métodos que emplea, como sí de su posibilidad de articular conceptos, sustentar principios y desechar posiciones equivocadas. ${ }^{1}$ Una

1. H. Schultz. "Statistics in Economics," Report of the Fourth Annual Research Conference on Economics and Statistics, Colorado Springs, CO: The Cowles Commission, 1938, p.38. investigación, particularmente de corte científico, por tanto, no es útil porque sus conclusiones y resultados se obtienen de invocar una teoría intelectualmente exigente que permite, a su vez, el desarrollo de un modelo matemático sofisticado y estimable mediante el empleo de complejas estadísticas y rigurosos métodos econométricos, sino porque necesariamente permite el uso de la teoría como principio organizacional para facilitar la exposición de conceptos y el empleo de herramientas y técnicas con las que el problema puede abordarse con mayor excelencia para obtener resultados robustos y conclusiones relevantes.

La tarea principal de un administrador de empresas es tomar decisiones ejecutivas que generen riqueza financiera para la organización y riqueza económica para la sociedad, mediante la generación de valor. Indubitablemente ello requiere de competencias varias. Entre lo necesario y sin perjuicio de lo dicho en el párrafo anterior, está la capacidad de formalizar cuantitativamente las decisiones importantes, sea mediante un modelo, una ecuación, un gráfico. En consecuencia, en esta revista prima el enfoque analítico del problema y si bien su exploración y desarrollo pueden llevarse a cabo cualitativamente, en la medida de lo posible, como de lo útil, se viabilizará y enriquecerá con el análisis cuantitativo propio del caso.

En cuanto a formato, la revista se ciñe a los estándares institucionales y normas internacionales de publicación y registro, tanto en su versión física, como en su versión virtual. En este sentido, se asume el compromiso de publicar opiniones, entrevistas, ensayos e investigaciones inéditas o bajo autorización, debidamente revisadas en cuanto a propiedad intelectual y valor al conocimiento, para lo que se someten a la evaluación de rigor por el Comité Editorial Internacional. Este comité, compuesto por intelectuales, autoridades académicas y empresarios de amplia y reconocida trayectoria, tiene como función principal la de velar por el rigor, la veracidad y la formalidad de los escritos que componen el íntegro de este y de cualquier otro número de la revista. Ante la excelencia como constante, nos complace informar de la incorporación de la Dra. Martie-Louise Verreynne, reconocida catedrática de la Escuela de Negocios de la Universidad de Queensland, Australia, como nuevo miembro de este comité revisor.

En cuanto a organización, la revista, en esta oportunidad, se compone de cuatro partes, que en su conjunto expone una variedad temática que evidencia nuestro deseo de generar 
para ella una amplia lectoría, vinculada laboral, profesional e intelectualmente al mundo de los negocios, sin sacrificar erudición. La primera parte presenta opiniones educadas sobre las áreas funcionales y los quehaceres habituales de la empresa privada. La segunda parte de la revista presenta una valiosa y oportuna entrevista a la Sra. Beatriz Boza, socia de Gobernanza y Sostenibilidad Corporativa en EY, sobre el papel medular del gobierno corporativo, tanto en la generación de transparencia en la toma de decisiones, a propósito de la actual crisis ético-institucional en la gestión empresarial y cuyo impacto en la economía no ha sido menor, como en la transformación de empresas medianas familiares en corporaciones. La tercera parte de la revista presenta 12 monografías de diverso corte, escritas por pensadores y analistas de universidades y centros de investigación locales, como extranjeros. La revista termina con la cuarta parte, en la que se reseña, tanto los premios Protagonistas del Cambio y Creatividad Empresarial--dos de las iniciativas de reconocimiento más emblemáticas de la UPC a la innovación-las tesis de nuestros colegas que se han doctorado recientemente, así como tres libros seleccionados para este número.

Entre los ensayos del presente número, debemos resaltar el de Tom Palmer (Cato Institute), quien transmite, con preocupación, el resurgimiento de los movimientos en contra del liberalismo clásico, como consecuencia de nuestro fracaso en explicar la moralidad del capitalismo; el de Soledad Escalante (Universidad Antonio Ruiz de Montoya), quien desarrolla una alturada discusión filosófica sobre el propósito de la empresa privada en una economía de mercado; el de Pablo San Martín y Orlando Llanos (Universidad Católica de la Santísima Concepción), en el que explican cómo en términos del gobierno corporativo se ha comenzado a replantear la forma de desarrollar el quehacer económico de la empresa, particularmente si de sostenibilidad en el tiempo se trata; $y$, finalmente, el ensayo de Luis García Corrochano (UPC), en el que desarrolla una discusión legal sobre la solución de controversias entre Estados en los tratados de libre comercio.

Es menester, asimismo, hacer hincapié en las investigaciones de Carlos Adrianzen (UPC), de Orlando Llanos, Pablo San Martín y Jonathan Cuevas (Universidad Católica de la Santísima Concepción) y de Osvaldo Cado (Pontifica Universidad Católica Argentina). Adrianzen presenta evidencia empírica adicional a favor de la apertura comercial como fuente generadora de riqueza económica para beneficio de la sociedad. Por su lado, Llanos et al. analizan el papel de la familia fundadora, como parte, en la configuración del gobierno corporativo. Y Cado, finalmente, hace uso de la teoría de juegos para desarrollar varios mecanismos con los que una economía en desarrollo puede evitar equilibrios sub-óptimos en materia fiscal debido a la evasión tributaria por la vigencia de altas tasas impositivas.
La Review of Global Management es una propuesta de la Facultad de Negocios de la UPC, en el marco de la excelencia académica, para estrechar vínculos con sus stakeholders y revalidar la presencia de la UPC en la sociedad peruana a través de su función como fuente educativa de calidad y generadora de conocimiento. Es la puesta en marcha de una idea indubitablemente ambiciosa y de largo aliento, intelectualmente exigente, que con la medida necesaria de humildad pero también con entusiasmo compartimos, confiando en su capacidad de estar a la altura de la crítica.

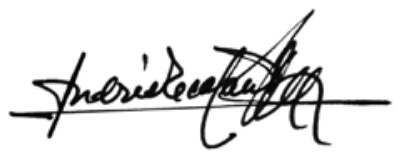

Andrés A. Escalante, Ph.D. -EDITOR GENERAL 